\title{
MONITORING LAND USE CHANGES AND SOIL DEGRADATION USING SPOT AND TEMPORAL AERIAL PHOTOGRAPH DATA - THE CASE OF VATHY BASIN (KALYMNOS ISLAND - DODECANESE GREECE)
}

\author{
Mimides T. ${ }^{1}$, Psomiadis E. ${ }^{2}$, and Trikili I. ${ }^{1}$ \\ 'Agricultural University of Athens, Department of Natural Resources \& Agricultural Engineering, \\ Section of Water Resources Management, Laboratory of Agricultural Hydraulics, Iera Odos 75, \\ 11855,Athens,teom@aua.gr \\ ${ }^{2}$ Agricultural University of Athens, Department of Geology Sciences \& Atmosphere Environment, \\ Laboratory of Mineralogy - Geology,Iera Odos 75,11855,Athens,mpsomiadis@aua.gr
}

\begin{abstract}
The present paper focuses on the usefulness of aerial photographs and satellite data in the multitemporal detection of land use changes, soil degradation and erosion. The study was carried out in the watershed of Vathy in the Kalymnos Island, and the study period spanned from 1960 to1999. Aerial photographs of two different periods of time and satellite SPOT data were used for this purpose. The synergistic use of a Geographical Information System for the manipulation of the data was the key for the Natural monitoring of the soil erosion and degradation.

The results revealed many changes in the cultivations and in the land use of the watershed the last decades. These changes supplemented by village expansion and spatial reduction of natural vegetation led to the acceleration of soil erosion, to the degradation of water supplies and generally to an environmental deterioration of the wider area.
\end{abstract}

Key words: Remote sensing, GIS, erosion, environmental deterioration.

\section{Пвріं}

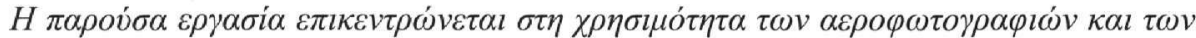

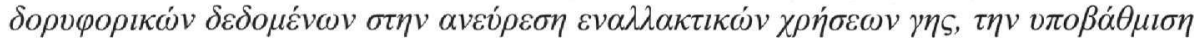

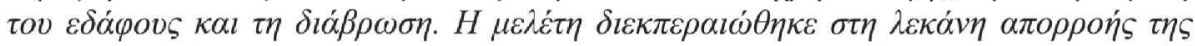

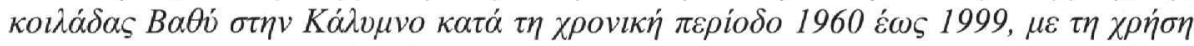

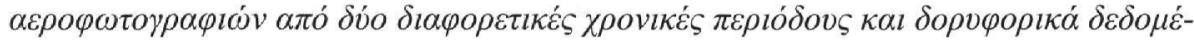

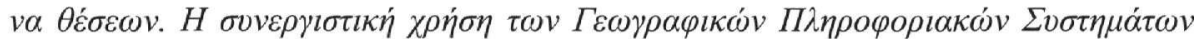

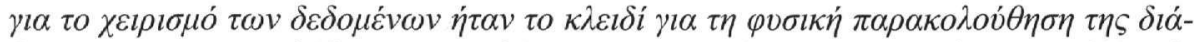

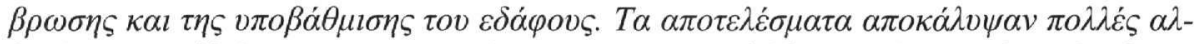

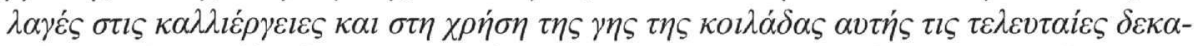

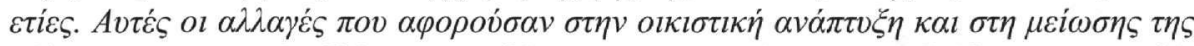

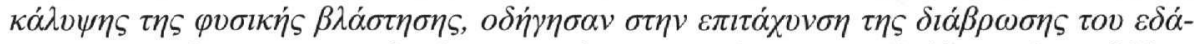

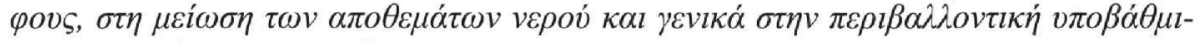

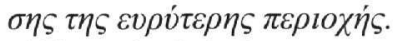

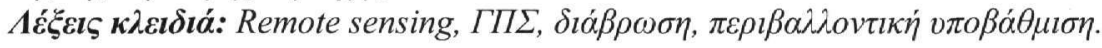




\section{Introduction}

Several regions around the world are currently undergoing rapid, wide-ranging changes in land cover. These changes in land use, and in particular in very susceptible island areas, have attracted attention because of the potential effects on erosion and land degradation, (Floras et al. 1999). Soil erosion and land degradation will perhaps be the main challenge to sustainable development for future generations, (Hurni 1997).

The study area at Kalymnos island, was focused on the watershed of Vathy, comprises a semiconfined small basin with NW-SE direction surrounded by mountainous masses with the same longitudinal parallel direction. The main water current, which drains the basin, discharges at the east side of the basin in Rina's bay.

Remote sensing and GIS techniques were chosen because they provide a viable tool and source of data from which updated land-cover information can be efficiently extracted in order to draw up an inventory and monitor the land use changes which lead to soil erosion and land degradation, (Gao et al. 1998). They offer the opportunity to gain fresh insights into biophysical systems through the spatial, temporal, spectral and radiometric resolutions of remote sensing systems and through the analytical and data integration capability of GIS, (Walsh et al. 1998). Remote sensing data to assess land degradation and erosion hazards are derived mainly from the visible and infrared bands, (King et al. 1993, Hill 1994).

The remotely sensed data available for this research consisted of SPOT multispectral images dating July 1998 and aerial photographs of 1960 and 1997. Principal Component Analysis (PCA) and Normalize Difference Vegetation Indices (NDVI) were applied in SPOT data in order to enhance the eroded areas.

The aim of this study concentrates on: (a) the exploitation of the sub areas affected by erosion and of the capability of remotely sensed data and GIS techniques to discriminate the degraded areas, and (b) the relation between parameters, such as, geomorphology, land cover/use and human activities that form an interactive natural/human system and how they influence the land degradation phenomenon.

\section{Description of the study area}

The island of Kalymnos belongs to the Dodecanese group of islands, Greece, and it is situated in the southeast Aegean sea (lat. $36^{\circ} 57^{\prime}$, long. $26^{\circ} 59^{\prime}$ ). The island lies $22 \mathrm{~km}$ west of Asia Minor, (Fig. 1).

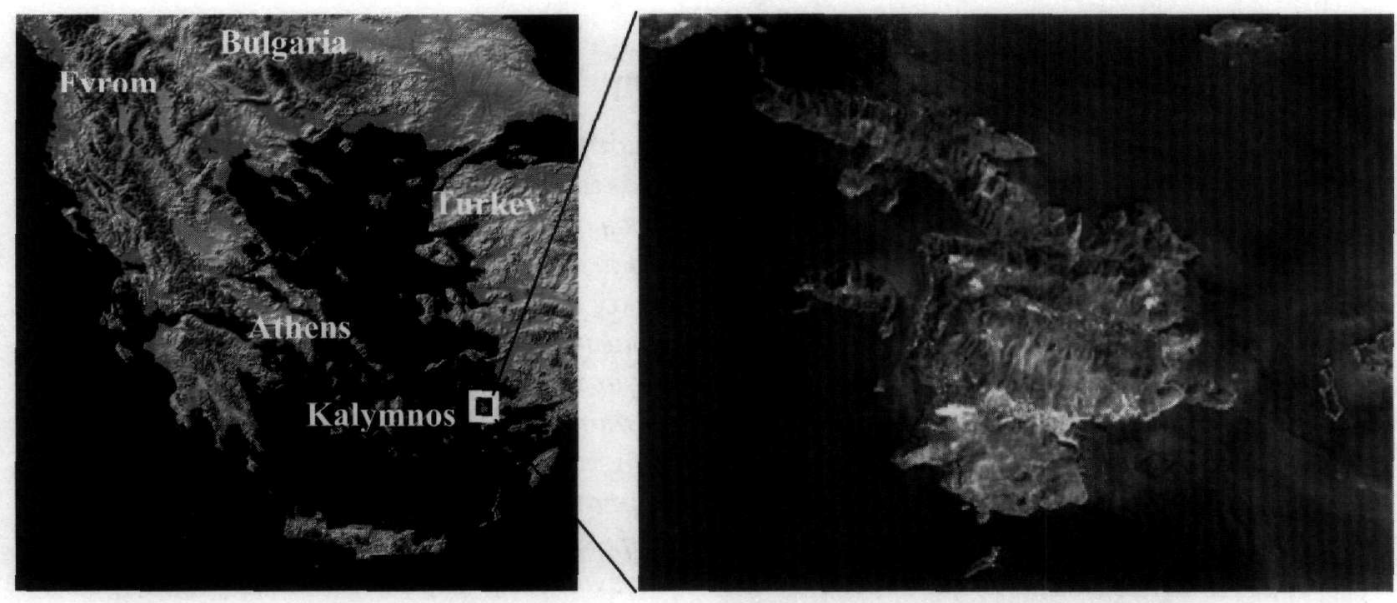

Figure 1 - Location of Kalymnos' island (red box) 
The population census according to the Hellenic Statistical Service (HSS) showed that the permanent inhabitants of the island increased from 14.249 in 1961 to 16.952 in 1999, (Mimides et al. 1992).

According to the system Bagnouls and Gaussen (1953), the climate of the study area is characterized as a dry warm Mediterranean with an intense dry period and a relatively warm and wet winter. The rainfall is relatively low (an average $521.3 \mathrm{~mm} /$ year) and homogenously allocated throughout the year, while snow does not exist. From the total annual rainfall, $287 \mathrm{~mm}$ or about $56 \%$ of the total rain, is observed usually during the winter months, while $46.1 \mathrm{~mm}$ or $8.8 \%$ approximately appears from April until September, which is the main period of growth of the majority of the plants.

Stratigraphically, Kalymnos is structured from the following units:

- Paleozoic Unit: It is the oldest unit and its deepest members mainly consist of thick-bedded white limestones and dolomite limestones. The intermediate members consist of dark thickbedded and thin-bedded limestones while the upper members, from shale, phyllite and clay schists with layers and limestone intercalations.

- Tectonic unit of amphibolites, schists and gneisses: the amphibolites appear in thin alternations between the schists and gneisses. They are fine-grained, middle-grained, grossgrained formations and their age is traced at the Upper Carboniferous.

- Tectonic unit of the Ionian Zone: This unit consists of sub-units as they are described below:

- Clastic base formations of upper Permian: They constitute the base of Ionian zone and consist of alternations of fine-grained to gross-grained sandstones, conglomerates, metashales, clay schists as well as micritic and breccial limestones.

- Triassic dolomites and dolomite limestones. They lay on the clastic base formation with a normal transition.

- Middle limestones, which constitute the normal upper development of the Triassic dolomites and dolomite limestones. The lower members are bituminous.

- Malmian - Cretaceous upper and middle limestones with chert.

- Tectonic unit of Gavrovos zone: This upper Jurassic - Cretaceous tectonic unit is represented by a limestone of considerable thickness.

- Neogene formations: They are occurring in many locations of the island, covering small areas. They consist of: white marls, yellow-red clays, clay-marls with a gray to gray-yellow color, white marl limestones, brown-gray and gray thin-middle and thick layered, conglomerates mainly with carbonate pebbles carbonic, and conglomerate with argillaceous-marly matrix. The Neogene formations are of limnetic origin and possibly of Pliocene age.

- Quaternary formations: They contain Pleistocene and Holocene formations, like:

- Pleistocene formations. Consolidated slide rocks and fan conglomerate. Volcanic tuffs, a volcanic pyroclastic formation with rhyolite as the main component.

- Holocene formations. They contain talus slope screes and detrital cones, terra-rossa alluvial valley deposits and coastal sands.

The lithological formations, that comprise the small drainage basin of Vathy, are displayed in Figure 2. 


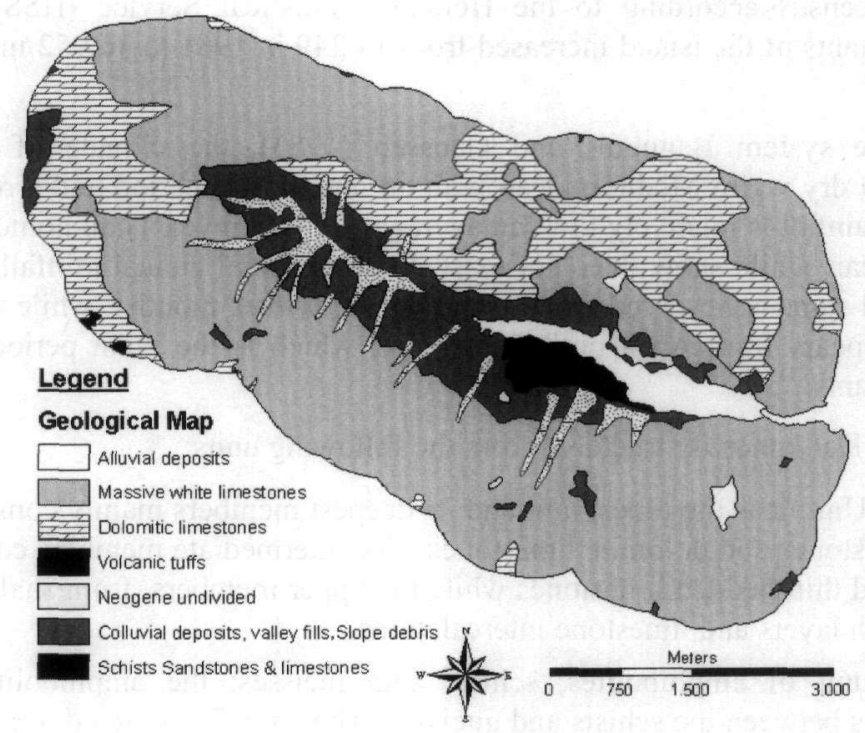

Figure 2 - Lithological map of the Vathy watersshed

\section{Role of remote sensing-GIS in land use alterations}

Preparation of land use maps by conventional methods is a very time consuming and laborious process. Remote sensing provides multi-spectral and multitemporal synoptic coverages for any area of interest. The satellite data provide a permanent and authentic record of the land use patterns of a particular area, at any given time, which can be re-used for verification and re-assessment. On the other hand, GIS offers a tool for integrating multi-disciplinary data leaking to dedicated interpretations in an easy and logical way. This integrated approach proves to be quick and costeffective.

\section{Raster and vector data set}

The data set used in this study consisted of:

1. Satellite SPOT1 (XS) images, three spectral bands, acquisition date 08/07/1997, sun elevation $70^{\circ}$, cloud free, lines/columns: $3005 \times 3248$, process level $1 \mathrm{~B}$.

2. Aerial photographs of the Hellenic Geographical Military Service (HMGS): Two kinds were used: acquisition date 15/09/1960 and high accuracy collection of acquisition date $22 / 06 / 1997$. The last is an orthorectified photo at $1 \mathrm{~m} /$ pixel resolution and played the role of reference image. Their scales were: 1:40.000 and 1:15.000 respectively.

3. Topographic maps of the HMGS and geological maps of the Institute of Geological \& Mineral Exploration-IGME, at 1:50.000 scales.

The digital image processing of the satellite data was carried out making use of the Integrated Land and Water Information System v.3.3 (ILWIS) software of ITC, while the manipulation of the spatial information and the digitizing of the thematic maps were made employing ILWIS and ArcGIS v.9. Supplementary field campaigns were performed in order to estimate the accuracy of the final results. 


\section{Manipulation of vector data}

The Digital Elevation Model (DEM) of the watershed was created employing 1:50.000 scale topographic maps. The contour lines were digitized with an interval of 10-20 meters for the flat areas to 40 meters at the highlands. Additionally, surface-specific point elevations, including high and low points, were digitized in order to improve the final digital product. A linear interpolation method was applied, based on the Bongefors distance method, (ILWIS User's Guide, 2001) aiming to the transformation of the contour data into a DEM, with a spatial resolution of 25 meters. With the intention of verifying its fidelity, the digital elevation model was plotted against the 1:50.000 scale contour maps, by interpolating the elevation values and overlapping them on the original topographic maps. This process led to a satisfactory coincidence of the corresponding contour lines. Also by adapting a smooth algorithm allowed the local slope-dependent errors to associate with the finite difference representation. The obtained resolution of the DEM was 20 m/pixel (Fig. 3a).

\section{Image Pre-processing}

All aerial photographs were scanned, radiometrically enhanced by using their histogram breakpoint editor and corrected geometrically, using image to image technique. The reference image for the geometric correction was a high accuracy collection of 1997 orthorectified aerial photographs at $1 \mathrm{~m}$ /pixel resolution. The photographs of 1960 were registered to the 1997 orthorectified photographs using a nearest neighbour resampling method. Finally, the histograms of the aerial photographs were matched and a mosaic image was created for each period (1960 and 1997) (Figs 3c, d accordingly).

The preprocessing of the SPOT XS data was concerning mainly the radiometric enhancement, and was performed by applying a linear contrast stretching and creating a new Look Up Table. Likewise, the images have been geometrically corrected by selecting a set of approximately 15 ground control points, derived from the high accuracy aerial photographs of 1997 and topographic maps (1:50.000) of the HAGS. The Digital Elevation Model was used for orthorectification and the nearest neighbour resampling method was applied in order to create the final output images with $20 \mathrm{~m}$ ground resolution, (Fig. 3b). Finally, a False Color Composite (FCC), with XS3, XS2, XS 1as Red, Green, and Blue was created in order to supplement the visual interpretation of the study area. This image was finally converted into a gray scale image.

The Principal Component Analysis (PCA) and the Normalize Difference Vegetation Index (NDVI) were applied on SPOT data in order a rational display of the phenomenon of the erosion to be achieved.

\subsection{Principal component analysis}

First the change detection technique of PCA was applied. This is considered a multi - variable statistical technique which, by choosing non-correlated linear composite variables (eigenvectors) binds each output principal component with linear change to display a minimum variance. Additionally, with their principal component axes to represent uncorrelated data, this methodology is employed to transform data for enhancing areas of local changes in multitemporal, multispectral images, (Singh et al. 1985, Fung et al. 1987, Psomiadis et al. 2005).

Here, the first principal component (PC1) corresponds to the brightest image (information concerning topography), while the second component (PC2) contains spectral information. PC3 contains a small amount of information and "noise". A false colour image has been composed by displaying, the $\mathrm{PC} 1$ as red, $\mathrm{PC} 2$ as green and the $\mathrm{PC} 3$ as blue.

Figure 4, represents a black and white image of the original false colour image. In this image, the severely eroded areas appear with dark grey shades. With light grey shades appear the bare soils and arable lands (without vegetation during summer period), including those that are mainly 

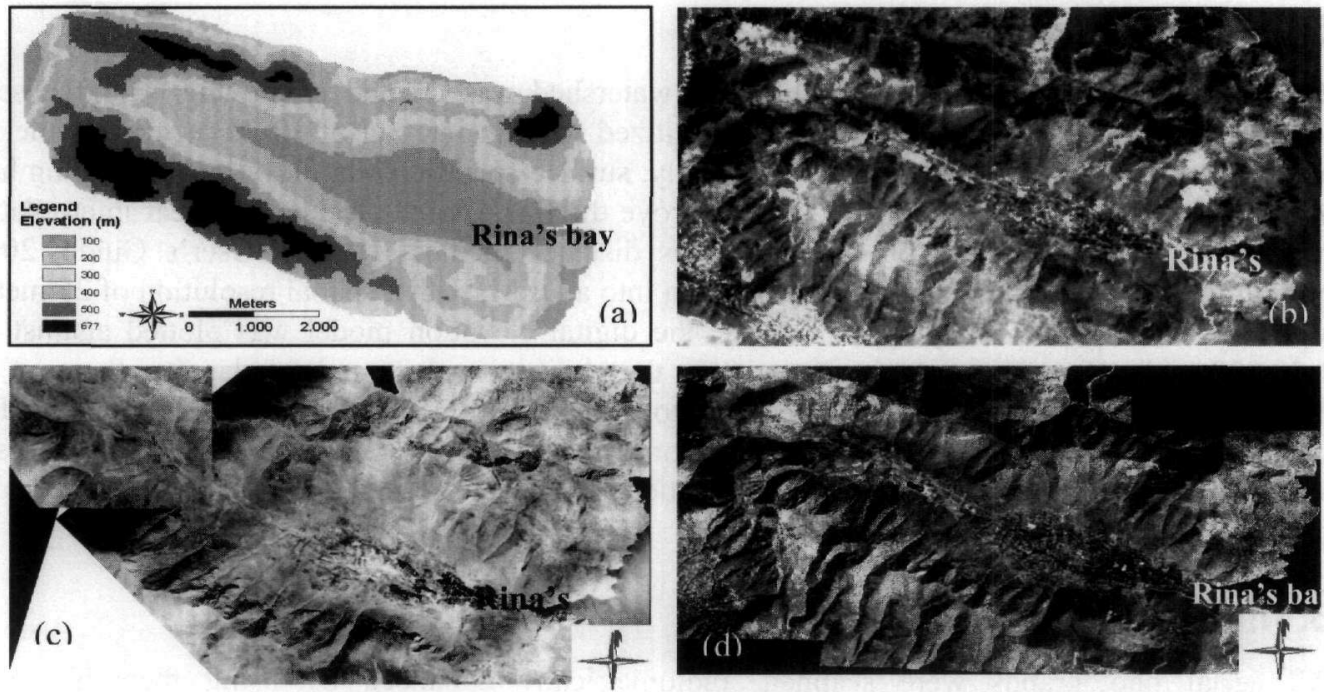

Figure 3 - (a) Digital Elevation Model (DEM), (b) False Color Composite of SPOT image (FCC), (c) Aerial photographs' mosaic of 1960, (d) Aerial photographs' mosaic of 1997

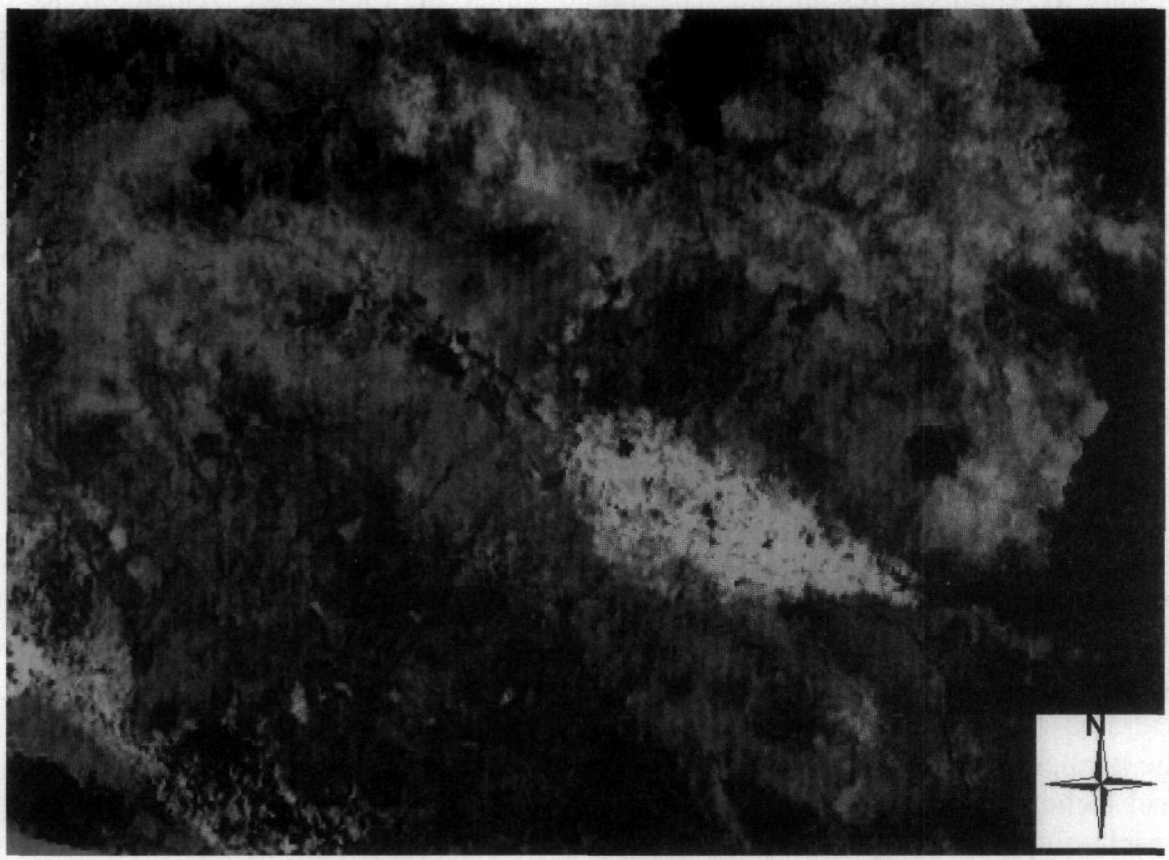

Figure 4 - Gray shades image of the false colour composite, by displaying PC1, PC2 and PC3 as red, green, blue

degraded. Moreover, with very dark grey shades to black are appearing some anthropogenic constructions such as roads and the unterminated ex river pond at the west side of the small basin. With very light grey shades to white appear the cultivations (citrus trees and crops) especially at the east side of the watershed, as well as some grasslands and shrubs located at small isolated mountainous areas. 


\subsection{Normalize Difference Vegetation Index (NDVI)}

Second the NDVI was employed in order to detect the distribution of vegetation and its density in the watershed by dividing the pixel brightness of Visible Red band (XS2) and Infrared band (XS3) to produce a new image, a method known as rationing:

$\mathrm{NDVI}=(\mathrm{XS} 3-\mathrm{XS} 2) /(\mathrm{XS} 2+\mathrm{XS} 3)$

$(\mathrm{XS} 2=$ visible band, $\mathrm{XS} 3=$ near infrared band $)$

The new product is a black and white image, where vegetated areas display high values due to the relatively high near-infrared reflectance and low reflectance in the visible band.

For the interpretation of the results the density slicing technique was applied. This technique classifies the values of a raster map. Ranges of values of the input map are grouped together into one output class (Fig. 5).

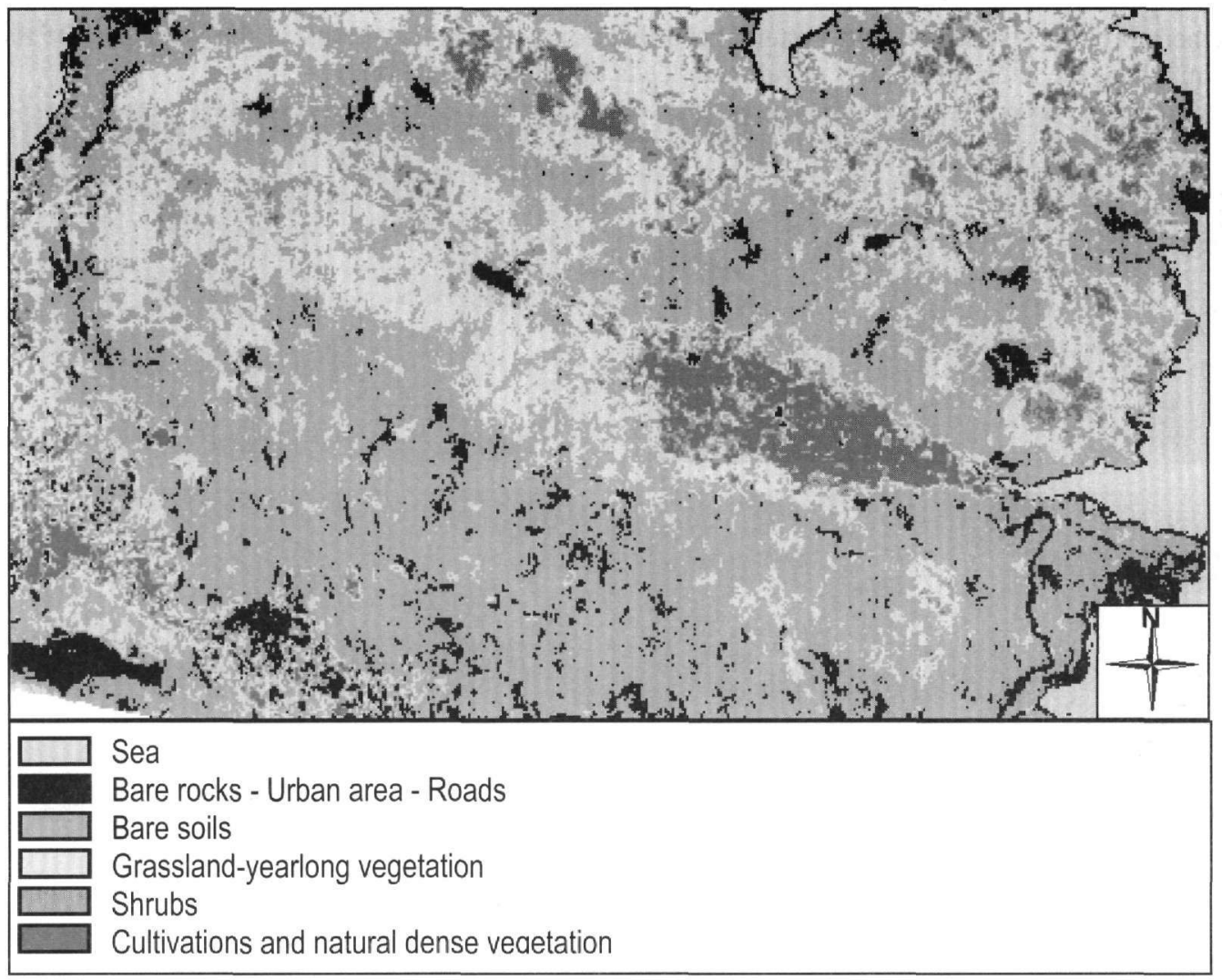

Figure 5 - The density slice image of the Normalize Difference Vegetation Index

\section{Results - Discussions}

Visual interpretation was used for the elaboration of the aerial photographs' mosaics leading to the necessary the information depicting changes that occurred during the period of 1960 to 1997. The main changes that perceived in the watershed are the following:

- The expansion of the settlements (Fig. 6a).

- The replacement of arable land from citrus trees, which display higher demand for irrigation water (Fig. 6b). 
- The expansion of cultivations (mainly arable crops and less olive trees) as well as several anthropogenic activities, such as the water reservoir at the west side of the basin (point 1 of Fig. 6c).

- The deforestation of the hills due to the fire incidents and overgrazing (points 2 and 3 of Fig. 6d).

The visual interpretation of the final satellite products and fieldwork showed that soil erosion seems rather severe, especially at the hilltops, and is associated with overgrazing, fire events and steep slopes. Moreover, the aeolian erosion processes at the hilltops are more effective when the surface is dry and free of vegetation (as appeared in NDVI). These parameters led to bare outcrops of the parent rocks.

On the other hand the increase on human population and the replacement of arable land with citrus trees increased the water demands of the watershed and led to the salinization and degradation of soils especially at the areas where the soil quality and slope steepness have a negative influence. Furthermore, the expansion and systematic utilization of the cultivations to the west part of the basin, where the soils was poorly developed, leeds to land degradation.
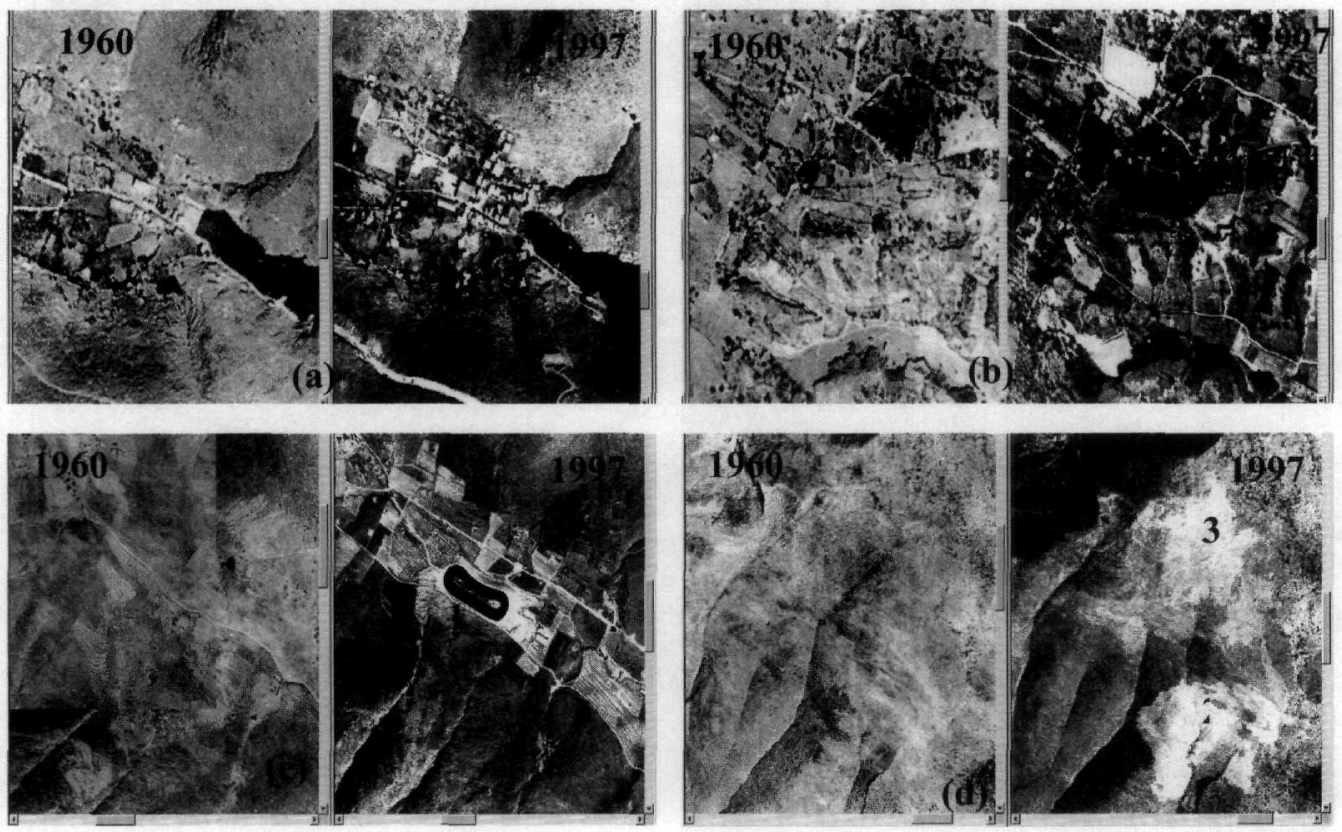

Figure 6 - Subsets of aerial photographs of 1960 and 1997, demonstrating various changes that took place in watershed the last 37 years

\section{Conclusions}

The watershed area is characterized as a fragile ecosystem, and very vulnerable to soil erosion and land degradation. Land use changes occurred the last decades deteriorated the area by increasing the erosion rates.

The remote sensing techniques proved to be appropriate methods for documenting and analyzing land degradation in semi-arid regions. Moreover, GIS proved as well as to be an excellent tool for studying the environment, offering means for combining different maps, variables and data from diverse sources.

It is true that for most of the landscapes of the Mediterranean Basins, when the problems of land degradation are tangible and thus detectable using remotely sensed data, it is often too late. Land 
and soil degradation has reached dramatic rates on our planet and will perhaps constitute the main challenge to sustainable development for future generations. For this reason, the use of geoinformation technologies can helps stakeholders to reorganize their planning and decisionmakers to plan sustainable land management and development.

\section{References}

Bagnouls, F., and Gaussen, H., 1953. Saison sèche et indice xérothermique, Docum. Pour les Cartes des Prod. Vèget. Série: Gènèralitè, 1, 1-49.

Floras, S. A., and Sguras, I. D., 1999. Use of geoinformation techniques in identifying and mapping of erosion in a hilly landscape of central Greece, $J A G, 1,68-77$.

Fung, T., and LeDraw E., 1987. Application of principal components analysis to change detection, Photogrammetric Engineering and Remote Sensing, 53, 1649-1658.

Gao, J., and Skillcorn, D., 1998. Capability of SPOT XS data in producing detailed land cover maps at the urban-rural periphery, Int. J. of Remote Sensing, 19, 2877-2891.

Hill, J., 1994. Land degradation and soil erosion hazard mapping in Mediterranean environments with operational earth observation satellites, Proc. Int. Symposium "Operazionalization of Remote Sensing”, ITC, Enschede, The Netherlands, 19-23 April, 9, 41-51.

Hurni, H., 1997. Concepts of sustainable land management, ITC Journal, 3/4, 210-215.

ILWIS 2.1 For Windows Applications guide, (October 1997). ILWIS Dept. ITC, p. 352, Netherlands.

King, C., and Delpont, G., 1993. Spatial assessment of erosion: contribution of remote sensing, a review, Remote Sensing Reviews, 7, 223-232.

Mavromatis, G. N., 1980. The bioclimate of Greece- Relations of Climate and Natural Vegetation, Bioclimatic Maps, Forest Research Foundation, Volume I, Appendix.

Mimides, Th., and Papadopoulos N., 1992. Hydrological study of Kalymnos Island, Vol. I - Main study, Vol. II - Appendix of Hydrochemistry, Vol. III - Geophysical exploration. It is accompanied by 27 maps outside the text.

Psomiadis, E., Parcharidis, I., Poulos, S., Stamatis, G., Migiros, G., and Pavlopoulos, A., 2005. Earth observation data in seasonal and long term coastline changes monitoring: the case of Sperchios River delta, Zeitschrift fur Geomorphologie, 137, 159-175, Berlin-Stuttgart.

Singh, A., and Harrison, A., 1985. Standarized Principal Components, Int. J. Remote Sensing, 6(6), 883-896.

USDA., 1975. Soil Taxonomy: A Basic System of Soil Classification for Making and Interpreting Soil Surveys. Soil Conseravation Service, U.S. Deep. Agric. Handb. No 436, 754 p.

Walsh, S.J., Butler, D.R., and Malanson, G.P., 1998. An overview of scale, pattern and process relationships in geomorphology: a remote sensing and GIS perspective. Geomorphology, 21(3-4), 183-205. 